\title{
VALUASI JASA LINGKUNGAN HUTAN TROPIS: STUDI KASUS BEBERAPA KAMPUNG DI KALIMANTAN TIMUR
}

\section{(ECOSYSTEM SERVICES VALUATION OF TROPICAL RAINFOREST: CASE STUDY OF SEVERAL VILLAGES IN EAST KALIMANTAN)}

\author{
Nuzula Elfa Rahma*, Erna Rositah*, Dwi Agung Pramono*, Dyah Widyasasi", \\ Fariyanti** $^{* *}$
}

\author{
*Politeknik Pertanian Negeri Samarinda \\ Jalan Sam Ratulangi Kelurahan Sungai Keledang, Samarinda \\ email: elfarahma@gmail.com \\ *** Politeknik Negeri Samarinda \\ Jalan Cipto Mangunkusumo, Kelurahan Sungai Keledang, Samarinda \\ Diterima: 15 Mei 2020; Direvisi: 2 Juni 2020; Disetujui: 13 Juni 2020
}

\begin{abstract}
ABSTRAK
Dalam perumusan kebijakan terkait pengelolaan lingkungan hidup, khususnya terkait ekosistem hutan hujan tropis di Kalimantan Timur, perlu didasarkan pada kajian yang berbasis sains. Dengan latar belakang tersebut, penelitian ini dilaksanakan. Adapun tujuan dari penelitian ini adalah untuk menentukan nilai manfaat jasa lingkungan dari keberadaan ekosistem hutan hujan tropis yang berada di kawasan beberapa kampung di Kalimantan Timur. Empat kampung yang menjadi area studi meliputi Bea Nehas, Merabu, Dumaring, dan Long Duhung. Valuasi dilakukan dengan metode benefit transfer, dengan memanfaatkan database TEEB (The Economics of Ecosystems and Biodiversity) sebagai acuan. Hasil studi menunjukkan bahwa TEV (Total Economic Value) untuk kampung Bea Nehas adalah sebesar 1,25 milyar USD/tahun atau setara dengan 18,2 triliun rupiah/tahun; TEV untuk kampung Merabu adalah sebesar 314,1 juta USD/tahun atau setara dengan 4,6 triliun rupiah/tahun; TEV untuk kampung Dumaring adalah sebesar 325,9 juta USD/tahun atau setara dengan 4,7 trilyun rupiah/tahun; sedangkan, kampung Long Duhung memiliki TEV sebesar 202,8 juta USD/tahun atau setara dengan 2,9 trilyun rupiah. Dari nilai TEV kampung-kampung tersebut, proporsi nilai jasa pendukung adalah sebesar $0,1 \%$, jasa penyediaan sebesar $45,2 \%$, jasa pengaturan sebesar 17,3\%, dan jasa kultural sebesar $37,4 \%$.
\end{abstract}

Kata kunci: jasa lingkungan, hutan hujan tropis, Kalimantan Timur, valuasi, TEEB database

\begin{abstract}
Policy formulation for environmental management needs to be founded by science-based evidence, particularly in regard of East Kalimantan tropical rainforest ecosystem. Thus, the establishment of this research. Moreover, the research aims to estimate the value of tropical rainforest ecosystem services in several villages within the boundary of the East Kalimantan province. The study takes into account four kampongs, Bea Nehas, Merabu, Dumaring, and Long Duhung. The valuation employs the benefit transfer method by using the TEEB (The Economics of Ecosystems and Biodiversity) database as reference. The result shows that the TEV (Total Economic Value) for Bea Nehas amounts to 1,25 billion USD/year, 314,1 million USD/year for Merabu, 325,9 million USD/year for Dumaring, and 202,8 million USD/year for Long Duhung. In term of TEV proportion, for all kampongs, supporting services take 0,1\%, provisioning services take 45,2\%, regulating services take 17,3\%, and cultural services take 37,4\%.
\end{abstract}

Keywords: ecosystem services, tropical rainforest, East Kalimantan, valuation, TEEB database 


\section{PENDAHULUAN}

Seberapa besar sesungguhnya nilai manfaat dari manfaat lingkungan, terutama dari ekosistem hutan tropis di Kalimantan Timur? Dalam kacamata pertumbuhan ekonomi, jasa lingkungan kerap kali diabaikan sebagai kontributor kesejahteraan. Keberlanjutan aspek lingkungan seringkali dianggap momok yang menghambat jalannya pembangunan. Kalimantan Timur telah lama menjadi tulang punggung perekonomian, tidak hanya di skala regional, namun juga nasional. Konsekuensinya adalah makin masifnya tekanan terhadap lingkungan, yang pada akhirnya menjadi faktor yang mempercepat degradasi lingkungan. Lebih jauh, efek dari degradasi lingkungan ini pada akhirnya juga akan menyentuh sisi perekonomian. Secara fundamental, ekonomi pada dasarnya mampu tumbuh karena adanya sumberdaya yang diperoleh dari lingkungan. Apabila kapasitas lingkungan untuk menyediakan sumberdaya terganggu atau bahkan hilang, bukankah perekonomian negara, pada satu titik juga akan mengalami kemunduran? Berangkat dari logika inilah maka muncul adanya pergeseran perspektif dalam memandang manfaat yang disediakan lingkungan. Tidak lagi hanya menggunakan paradigma aspek ekonomi, namun juga mencakup aspek ekologi dan sosial. Dari sinilah studi mengenai jasa lingkungan mulai berkembang.

Secara definisi, jasa lingkungan adalah segala manfaat yang diperoleh manusia dari lingkungannya (Millennium Ecosystem Assesment, 2005). Adapun secara historis, konsep jasa lingkungan mulai berkembang di era 1970an, dan mulai masuk menjadi bagian dari agenda arus utama terkait lingkungan di era 1990an, ditandai dengan berkembangnya upaya mengetahui seberapa bernilainya jasa lingkungan dalam perspektif ekonomi (Gómez-Baggethun, 2010). Secara sistematis, MEA membagi jasa lingkungan dalam empat kategori utama yaitu: jasa penyediaan (provisioning), pengaturan (regulating), penyokong/pendukung (supporting), dan kultural. Sistematika ini kemudian menjadi dasar dalam proses estimasi valuasi ekonomi terhadap jasa lingkungan suatu ekosistem.

Di tingkat masyarakat akar rumput yang tinggal di sekitar hutan, ketergantungan terhadap jasa lingkungan dari hutan tropis tidak hanya sangat tinggi tapi juga kompleks. Fungsi hutan bagi kelompok ini sudah bersifat multi-dimensi, dimana nilai manfaat hutan tidak hanya dimaknai pada hal-hal yang bersifat material dan langsung dapat dirasakan, akan tetapi juga mencakup hal-hal yang bersifat non-material. Selain untuk keberlanjutan yang bersifat fisik, hutan juga menjadi manifestasi pemenuhan kebutuhan masyarakat akan aspek identitas, spiritualisme dan aktualisasi diri. Kondisi ini menempatkan masyarakat di sekitar hutan sebagai pemangku kepentingan yang paling rentan posisinya apabila kehilangan manfaat hutan. Oleh karena itu kebijakan yang berpihak pada kelestarian ekosistem hutan tropis di Kalimantan Timur adalah sangat krusial.

Perumusan kebijakan tentunya perlu memiliki dasar kajian lingkungan hidup yang komprehensif dan strategis. Salah satu instrumen yang lazim digunakan adalah pendekatan valuasi jasa lingkungan. Dalam valuasi lingkungan, manfaat jasa lingkungan disajikan atau dikuantifikasi dalam nilai moneter. Hal ini dilakukan dengan harapan agar proses penyampaian informasi kepada perumus kebijakan terkait dapat lebih mudah dimengerti. Dengan latar belakang tersebut, penelitian ini dilaksanakan. Tujuan dari penelitian ini adalah untuk menentukan nilai jasa lingkungan dari keberadaan ekosistem hutan hujan tropis yang berada di kawasan beberapa kampung di Kalimantan Timur.

\section{METODE}

Dalam penelitian ini, ruang lingkup area penelitian difokuskan pada empat kampung yang berada di wilayah Kalimantan Timur, yaitu kampung Bea Nehas, Merabu, Dumaring, dan Long Duhung. Dalam penelitian ini, jasa lingkungan yang diperhitungkan didasarkan pada kategori jasa lingkungan oleh Millennium Ecosystem Assessment (2005) yang terdiri dari: 1) jasa pendukung (siklus nutrien, pembentukan tanah, dan produksi primer), 2) jasa penyediaan 
(biodiversitas, energi, sumberdaya genetik, air, dan pangan), 3) jasa pengaturan (pengendalian limbah, pencegahan banjir, siklus nutrien, pencegahan erosi, penyerbukan, pengaturan siklus air, dan pengaturan iklim), dan 4) jasa kultural (rekreasi, estetika, ekowisata, spiritual).

Valuasi jasa lingkungan dilakukan dengan menggunakan metode benefit transfer. Dengan metode ini, nilai jasa lingkungan didasarkan pada data penelitian valuasi jasa lingkungan yang sudah dilakukan (Johnston dkk, 2015). Acuan penentuan valuasi dari masing-masing jasa tersebut adalah data-data penelitian yang terhimpun dalam TEEB database (Van der Ploeg \& de Groot, 2010). Data penelitian yang dijadikan acuan dipilih berdasarkan kesesuaian lokasi area dan tipe ekosistem. Idealnya area studi pembanding juga berlokasi di pulau Kalimantan, baik yang berada di Indonesia, maupun Malaysia dan Brunei Darussalam. Jika tidak ditemukan, maka dipilih studi pembanding yang berada di kawasan paling dekat dengan Kalimantan. Dalam hal ini luasan lingkup kawasan dapat meliputi kawasan Indonesia, atau lebih luas lagi seperti Asia Tenggara, atau negara-negara yang berada di khatulistiwa seperti kawasan Asia Selatan dan Amerika Selatan.

Karena hasil studi yang digunakan umumnya merupakan publikasi dari beberapa tahun sebelumnya, maka nilai moneter yang ada disesuaikan untuk tahun 2019 dengan mempertimbangkan discount rate yaitu 3\% per tahun. Satuan nilai ekonomi jasa lingkungan yang digunakan adalah USD/ha/tahun. Nilai ini kemudian dikalikan dengan luas lahan hutan yang berada di kawasan kampung terkait. Dengan demikian didapatlah nilai TEV (Total Economic Value) dari masing-masing kampung.

Setelah estimasi nilai jasa lingkungan, tahap selanjutnya adalah melakukan analisa validasi dengan tujuan menginvestigasi faktor kesenjangan (gap) dan ketidakpastian (uncertainty) dari hasil studi ini. Dengan demikian dapat dilihat bagaimana nilai valuasi itu dapat merepresentasikan realitas. Sebagai dasar analisa validasi, metode yang dilakukan adalah dengan mengumpulkan data primer melalui pelaksanaan FGD (Focus Group Discussion) di kampung-kampung yang bersangkutan, penyebaran kuesioner dan wawancara dengan narasumber relevan yaitu kepala kampung, pemuka adat, serta beberapa anggota masyarakat. Validasi juga dilakukan dengan melakukan tinjauan literatur-literatur yang relevan. Validasi nilai jasa lingkungan ini disajikan secara kualitatif deskriptif.

\section{HASIL DAN PEMBAHASAN}

\section{Gambaran Umum Ruang Lingkup Area}

\section{1) Kampung Dumaring}

Kampung ini terletak di Kecamatan Talisayan, Kabupaten Berau. Masyarakatnya heterogen, terdiri dari suku Bugis (mayoritas), Jawa, NTT, serta suku Dayak Baluy sebagai suku asli. Sebagian besar beragama Islam, dan sisanya Katolik dan Protestan. Jumlah penduduk pada tahun 2018 tercatat sebesar 1.363 orang. Penduduk awal yang mendiami Kampung Dumaring adalah suku Dayak Baluy. Catatan paling awal mengenai kampung ini adalah di tahun 1790, dimana kampung ini tercatat sebagai bagian dari Kesultanan Sambaliung Berau. Masyarakat kampung ini memiliki sumber mata pencaharian yang cukup beragam, dimana sebagian besar berada di sektor non-formal yaitu buruh bangunan, buruh tani, petani musiman, dan perkebunan kelapa. Sebagian bekerja di sektor formal yaitu PNS pemerintah daerah, honorer, guru, tenaga medis, dll. Secara perekonomian, masyarakat Dumaring dapat digolongkan sebagai miskin, sangat miskin, dan sedang (Pemerintah Kampung Dumaring, 2018).

\section{2) Kampung Bea Nehas}

Bea Nehas terletak di Kecamatan Muara Wahau, Kabupaten Kutai Timur. Masyarakat Bea Nehas relatif homogen, dimana sekitar $90 \%$ etnis yang mendiami desa ini adalah dari suku Dayak Wehea, meski ada pula sebagian kecil berasal dari suku Jawa dan suku lainnya. 
Masyarakat umumnya beragama Katolik (86\%), Protestan (4\%) dan Islam (10\%). Jumlah penduduk tercatat sebanyak 767 jiwa Bea Nehas telah eksis sejak ratusan tahun yang lalu. Penduduk asli Bea Nehas meyakini bahwa mereka adalah sub-etnis Dayak tertua yang mendiami Kalimantan. Masyarakat Bea Nehas menghuni bantaran sungai Tlan (atau sungai Telen), yang tergambar dari kata Bea Nehas sendiri yang berarti "kampung yang berdiri di atas pasir/koral". Secara umum, perekonomian masyarakat Bea Nehas saat ini banyak bergantung pada perkebunan sawit (85\%) baik yang dikelola secara mandiri oleh masyarakat, maupun dengan skema plasma atau bermitra dengan perusahaan yang beroperasi di daerah tersebut. Tingkat pendidikan masyarakat rata-rata hanya sampai tingkat SD atau SMP. Masyarakat Bea Nehas relatif masih memegang teguh adat istiadat, bahasa, serta ritual keagamaan mereka (Pemerintah Desa Bea Nehas, 2018).

\section{3) Kampung Long Duhung}

Kampung Long Duhung terletak di Kecamatan Kelay, Kabupaten Berau. Dihuni oleh Dayak Mapnan, dengan jumlah penduduk pada tahun 2018 tercatat sebanyak 143 jiwa. Lokasi Kampung Long Duhung sering berpindah-pindah, dengan pola semakin ke arah hilir sungai. Pada tahun 1950-an Long Duhung terletak di muara sungai Duhung (anak sungai Kelay) sebelum akhirnya menetap di lokasi sekarang. Sebelum tahun 1970an, mata pencaharian penduduk didominasi oleh pola pemburu pengumpul. Setelah tahun 1970an, penduduk Long Duhung mulai mengenal pertanian, walaupun tetap menerapkan pola pemburu-pengumpul (Pemerintah Kampung Long Duhung, 2018).

\section{4) Kampung Merabu}

Kampung Merabu terletak di Kecamatan Kelay, Kabupaten Berau. Kampung ini terletak di hilir sungai Lesan, serta masih berada di kawasan karst Mangkaliat. Jumlah penduduk tercatat pada tahun 2017 adalah 231 jiwa. Penduduk asli kampung ini adalah suku Dayak Lebo yang juga hingga saat ini masih merupakan etnis mayoritas. Masyarakat umumnya beragama Kristen (55\%) dan Islam (45\%). Dari sisi mata pencaharian, sektor informal lebih mendominasi, yaitu petani dan buruh. Sebagian kecil ada yang merupakan pegawai baik yang berstatus pegawai pemerintah maupun swasta. Pemerintah desa cukup aktif berperan dalam membangun ekonomi kampung, yang ditunjukkan dengan berkembangnya pengelolaan usaha milik desa yang meliputi ekowisata, Pembangkit Listrik Tenaga Surya (PLTS), ternak sapi, usaha madu, dll (Pemerintah Kampung Merabu, 2018).

\section{Valuasi Jasa Lingkungan}

Berikut adalah hasil valuasi dari jasa ekosistem yang melingkupi jasa pendukung, penyediaan, pengaturan, dan kultural.

\section{1) Jasa pendukung}

Jasa pendukung merupakan jasa lingkungan yang paling fundamental karena jasa inilah yang menyokong kelangsungan jasa lingkungan yang lain (penyediaan, pengaturan, maupun kultural). Namun dalam studi ini estimasi nilai jasa pendukung menunjukkan nilai yang kurang signifikan dan hanya mengambil porsi $0,1 \%$ dari TEV. Nilai manfaat jasa pendukung untuk masing-masing kampung dapat dilihat pada Tabel 1.

Kesenjangan dan ketidakpastian. Secara intuitif, sebagai jasa yang paling esensial, nilai valuasi jasa kategori inilah yang harusnya paling signifikan. Namun tidak demikian hasil yang didapat dalam studi ini. Mengapa demikian? Salah satu faktornya adalah dalam database TEEB hanya tersedia data acuan untuk siklus nutrien, sedangkan untuk jasa pembentukan tanah dan produksi primer belum tersedia. Faktor lainnya adalah nilai acuan untuk siklus nutrien adalah 32,2 USD/ha/tahun, besaran ini jauh di bawah nilai acuan beberapa jasa lingkungan pada kategori jasa penyediaan. Hal ini terkait metode yang dilakukan dalam studi acuan. Studi 
tersebut menggunakan metode avoided cost, dimana valuasi jasa lingkungan didasarkan pada perhitungan biaya yang dapat dihindari akibat hilangnya jasa lingkungan tersebut, baik dari aspek kerugian hilangnya aset akibat bencana, biaya perbaikan/rehabilitasi, atau biaya barang substitusi (Mavsar dkk., 2013). Lesser \& Feinstein (1999) mengemukakan bahwa kekurangan metode ini adalah sulitnya memperhitungkan faktor ketidakpastian di waktu yang akan datang. Dalam konteks studi acuan, valuasi jasa siklus nutrien dikuantisasi berdasarkan biaya yang dapat dihindari dari aspek penggunaan pupuk (barang substitusi). Studi acuan tidak memperhitungkan ongkos yang mungkin muncul akibat eksternalitas negatif yang tidak dapat diatasi dengan aplikasi pupuk. Apalagi berbagai studi telah menunjukkan bahwa aplikasi pupuk sendiri juga memiliki potensi dampak lingkungan yang cukup serius (Chandini dkk., 2019; Viets \& Lunin., 1975). Apabila eksternalitas negatif tersebut diperhitungkan, nilai valuasi siklus nutrien tentu akan jauh lebih besar.

Tabel 1. Nilai manfaat jasa pendukung di empat kampung studi

\begin{tabular}{llccccc}
\hline \multirow{2}{*}{ No. } & \multirow{2}{*}{ Jasa pendukung } & \multicolumn{5}{c}{$\begin{array}{c}\text { Nilai Valuasi } \\
\text { (juta USD) }\end{array}$} \\
\cline { 3 - 6 } & & Bea Nehas & Merabu & Dumaring & Long Duhung & \\
\hline 1. & Siklus Nutrien & 1,4 & 0,3 & 0,4 & 0,2 & $100 \%$ \\
2. & Pembentukan Tanah & N/A & N/A & N/A & N/A & - \\
3. & Produksi Primer & N/A & N/A & N/A & N/A & - \\
& Total & $\mathbf{1 , 4}$ & $\mathbf{0 , 3}$ & $\mathbf{0 , 4}$ & $\mathbf{0 , 2}$ & \\
\hline
\end{tabular}

Sumber: hasil pengolahan data (2019)

\section{2) Jasa penyediaan}

Jasa penyediaan merupakan jasa lingkungan yang dapat dirasakan secara aktual dan langsung manfaatnya (tangible). Hal ini dikarenakan jasa-jasa lingkungan dalam kategori ini relatif bersifat konsumtif, contohnya pangan dan air. Dapat dilihat bahwa energi mengambil proporsi yang paling besar untuk kategori jasa penyediaan yang diikuti dengan sumberdaya genetik. Nilai jasa-jasa tersebut sangat kontras dengan jasa lingkungan pangan dan air, yang hanya mengambil porsi kurang dari $2 \%$. Meski jika dicermati dari besarannya, nilai jasa pangan dan air sesungguhnya cukup besar. Nilai jasa air berada di kisaran 200 ribu - 1,4 juta USD, atau setara dengan 2,9-20,3 milyar rupiah/tahun. Namun tentu saja nilai ini tidak sebanding dengan nilai jasa lingkungan energi yang kisarannya dapat mencapai 293,3 juta USD/tahun atau setara dengan 4,3 trilyun rupiah/tahun. Nilai manfaat untuk jasa penyediaan masing-masing kampung dapat dilihat pada Tabel 2.

Kesenjangan dan ketidakpastian. Faktor yang mengakibatkan kesenjangan antara jasa lingkungan sumberdaya genetik dan energi dengan jasa lingkungan lainnya di atas pada dasarnya terletak pada bias preferensi. Sebagai contoh, untuk pangan dan air, studi acuan menggunakan lingkup ekonomi lokal dalam pendekatannya. Nilai dalam valuasi didasarkan pada harga di pasar lokal (Secretariat of the Convention on Biological Diversity, 2001). Sehingga persepsi yang digunakan dalam penentuan nilai suatu manfaat adalah berasal dari sudut pandang masyarakat yang bersifat komunal. Dalam unit masyarakat ini, relasi sosial masih relatif erat. Dimana pihak pengguna/pembeli, penjual, dan pihak yang melakukan proses produksi/ekstraksi relatif tidak berjarak, bahkan dapat berinteraksi langsung. Dalam situasi demikian, masyarakat kurang memiliki motivasi untuk mendapatkan keuntungan yang sebesarbesarnya, dan lebih mengedepankan terjalinnya hubungan sosial yang baik. Selain itu, masyarakat juga hanya terfokus pada manfaat dalam kerangka "saat ini", kurang memikirkan potensi manfaat yang lebih besar di masa yang akan datang. 
Tabel 2. Nilai manfaat jasa penyediaan di empat kampung studi

\begin{tabular}{|c|c|c|c|c|c|c|}
\hline \multirow[t]{2}{*}{ No. } & \multirow[t]{2}{*}{ Jasa penyediaan } & \multicolumn{4}{|c|}{$\begin{array}{c}\text { Nilai Valuasi } \\
\text { (juta USD/tahun) }\end{array}$} & \multirow[t]{2}{*}{ Persentase } \\
\hline & & Bea Nehas & Merabu & Dumaring & Long Duhung & \\
\hline 1. & Pangan & 8,9 & 2,2 & 2,3 & 1.4 & $1,6 \%$ \\
\hline 2. & Air & 1,4 & 0,3 & 0,3 & 0,2 & $0,2 \%$ \\
\hline 3. & Sumberdaya Genetik (Genepool) & 232,2 & 58,2 & 60,4 & 37,6 & $41,0 \%$ \\
\hline 4. & Energi & 293,3 & 73,5 & 76,3 & 47,5 & $51,8 \%$ \\
\hline 5. & Bahan mentah & 22,1 & 5,5 & 5,7 & 3,6 & $3,9 \%$ \\
\hline \multirow[t]{2}{*}{6.} & Biodiversitas & 8,0 & 2,0 & 2,1 & 1,2 & $1,4 \%$ \\
\hline & Total & 565,7 & 141,9 & 147,2 & 91,6 & \\
\hline
\end{tabular}

Sumber: hasil pengolahan data (2019)

Pada studi yang menjadi acuan dalam valuasi jasa lingkungan energi dan sumberdaya genetik, setidaknya ada dua dimensi penting yang menyebabkan mengapa jangkauan nilai manfaatnya menjadi sangat besar. Yang pertama adalah adanya proyeksi potensi manfaat. Metode dalam valuasi energi dan sumberdaya genetik tidak hanya memperhitungkan nilai dalam kerangka "saat ini", namun juga memperhitungkan potensi manfaat yang mungkin didapat di masa depan. Akumulasi dari kantung-kantung potensi tersebut tentunya memperbesar nilai manfaat yang ada. Dimensi kedua, preferensi yang digunakan adalah preferensi industri dengan skala multi-nasional. Dalam hal ini, nilai manfaat didasarkan pada seberapa besar pelaku industri berani mengeluarkan uang (willingness to pay) untuk membeli "informasi" genetik (metode kontingensi). Dalam kasus ini, responden umumnya berasal dari kalangan industri obat-obatan, yang tentu saja orientasinya adalah mendapatkan keuntungan yang sebesar-besarnya.

Persepsi masyarakat. Dalam konteks persepsi masyarakat, secara keseluruhan mereka berpendapat bahwa jasa penyediaan air merupakan manfaat hutan yang paling penting keberadaannya. Hal ini erat kaitannya dengan relasi masyarakat empat kampung tersebut dengan sungai sebagai sumber air. Masyarakat kampung Bea Nehas, Dumaring, dan Long Duhung secara langsung menggunakan air sungai untuk keperluan konsumsi, dan MCK (mandi, cuci, dan kakus). Sedangkan sebagian besar masyarakat kampung Dumaring memanfaatkan air sungai dengan terlebih dahulu diolah melalui PDAM setempat. Hasil valuasi penyediaan air sesungguhnya hanya secara parsial merefleksikan signifikansi jasa penyediaan air. Apabila metode valuasi yang digunakan adalah metode avoided cost, ada kemungkinan nilai valuasi penyediaan air dapat lebih mendekati nilai manfaat sumberdaya genetik dan energi. Berbeda dengan siklus nutrien, indikator kerugian akibat ketiadaan jasa penyediaan air relatif lebih konkrit, sehingga lebih mudah diukur. Akan tetapi sayangnya data studi tersebut belum tersedia di database TEEB.

Selain air, jasa penyediaan pangan dan bahan mentah juga dipandang sangat penting. Salah satu keluhan dari masyarakat Bea Nehas terkait dampak hilangnya hutan adalah makin sulitnya melakukan kegiatan berburu dan mengumpul. Pada dekade 90 -an mereka hanya perlu bepergian tidak jauh dari kampung untuk mencari buah-buahan, babi, rusa, rotan, dan material lainnya. Namun saat ini jauh lebih sulit, perlu melakukan perjalanan menggunakan ketinting (perahu) selama satu hari untuk dapat mencapai lokasi yang sumberdayanya masih berlimpah. Kampung Merabu yang kondisi hutan desanya jauh lebih baik, pemanfaatan hutan sebagai sumber pangan dan bahan mentah masih eksis. Bahkan produk madu dari Merabu sudah dikelola dengan standar industri. Di Long Duhung, dengan pola hidup yang masih memegang tradisi berburu 
dan mengumpul, praktis masyarakat sangat tergantung dengan penyediaan pangan dan bahan mentah dari hutan.

\section{3) Jasa pengaturan}

Nilai manfaat dari jasa pengaturan menunjukkan bahwa pencegahan erosi mengambil porsi yang sangat besar, yaitu 66,1\%. Untuk Bea Nehas contohnya, nilainya mencapai 143,5 juta USD, yang kemudian diikuti oleh jasa pengaturan iklim. Kedua jasa lingkungan ini mendominasi dalam kategori jasa pengaturan. Adapun total manfaat jasa pengaturan untuk masing-masing kampung dapat dilihat pada Tabel 3.

Tabel 3. Nilai manfaat jasa pengaturan di empat kampung studi

\begin{tabular}{|c|c|c|c|c|c|c|}
\hline \multirow[t]{2}{*}{ No. } & \multirow[t]{2}{*}{ Jasa pengaturan } & \multicolumn{4}{|c|}{$\begin{array}{l}\text { Nilai Valuasi } \\
\text { (juta USD) }\end{array}$} & \multirow[t]{2}{*}{ Persentase } \\
\hline & & Bea Nehas & Merabu & Dumaring & Long Duhung & \\
\hline 1. & Pengaturan iklim & 37,9 & 9,5 & 9,9 & 6,1 & $17,5 \%$ \\
\hline 2. & Pengaturan aliran air & 2,6 & 0,7 & 0,7 & 0,4 & $1,2 \%$ \\
\hline 3. & Penyerbukan & 6,0 & 1,5 & 1,5 & 0,9 & $2,7 \%$ \\
\hline 4. & pencegahan erosi & 143,5 & 36,0 & 37,3 & 23,2 & $66,1 \%$ \\
\hline 5. & Pencegahan banjir & 13,5 & 3,4 & 3,5 & 2,2 & $6,2 \%$ \\
\hline \multirow[t]{2}{*}{6.} & Pengendalian limbah & 13,6 & 3,4 & 3,5 & 2,2 & $6,3 \%$ \\
\hline & Total & 217,1 & 54,4 & 56,5 & 35,2 & \\
\hline
\end{tabular}

Sumber: hasil pengolahan data (2019)

Kesenjangan dan ketidakpastian. Dapat dilihat bahwa pencegahan erosi sangat mendominasi nilai manfaat dari jasa pengaturan. Mengapa demikian? Dari studi acuan, nilai manfaat pencegahan erosi dikuantifikasi dengan metode avoided cost. Hasil studi tersebut menunjukkan bahwa dampak erosi ternyata jangkauannya sangat luas. Mencakup berbagai sektor penghidupan masyarakat yaitu pertanian, kehutanan, dan pariwisata (van Bekuering dkk, 2003). Variabel kerugian lainnya adalah potensi degradasi lahan yang akan sangat sulit direhabilitasi pada beberapa tahun ke depan. Sehingga lahan tersebut tidak dapat diusahakan kembali. Potensi kerugian dari adanya erosi relatif lebih mudah diukur karena sifatnya aktual, dimana dampaknya relatif langsung dapat dirasakan masyarakat. Dengan kata lain, faktor ketidakpastian pada valuasi jasa pencegahan erosi relatif kecil.

Lain halnya dengan jasa pengaturan iklim, dimana dampak negatif dari perubahan iklim bersifat inkremental dan dalam jangka waktu yang sangat panjang. Artinya faktor ketidakpastian sangat besar, sesuai dengan apa yang dikemukakan Lesser \& Feinstein (1999) di sub-bab sebelumnya. Sehingga penggunaan metode avoided cost kurang tepat. Pengaturan iklim umumnya dikuantifikasi dengan metode kontingensi, yang sangat bergantung dengan preferensi manusia sebagai respondennya. Masalahnya manusia secara intuitif tidak dirancang untuk dapat menghubungkan alur sebab-akibat dari penambahan temperatur udara sebesar $1{ }^{\circ} \mathrm{C}$ dengan meningkatnya frekuensi terjadinya cuaca ekstrem. Sehingga manusia cenderung untuk meremehkan dampak negatif dari hilangnya jasa pengaturan iklim. Konsekuensi finalnya adalah ada dimensi yang hilang atau tidak direpresentasikan secara utuh (Pascual dkk, 2012).

Persepsi masyarakat. Dari konteks persepsi masyarakat kampung, preferensi mereka secara umum menunjukkan konsistensi, yaitu penekanan terhadap pentingnya keberadaan hutan untuk keberlangsungan air. Tentu perlu dicatat bahwa masyarakat umumnya tidak membedakan antara jasa penyediaan air dan jasa pengaturan aliran air. Di Bea Nehas, masyarakat cukup terekspos dengan informasi bencana banjir yang sering terjadi di wilayah lain, sehingga sebagian kecil anggota masyarakat telah sadar pentingnya jasa pencegahan 
banjir, meskipun bencana banjir besar tidak pernah melanda kampung mereka. Di kampung Merabu, Long Duhung, dan Dumaring, pengakuan terhadap peran pencegahan banjir relatif tidak muncul. Terlihat bahwa ada semacam paradoks. Di wilayah yang sangat jarang mengalami banjir, manfaat pencegahan banjir justru luput dari kesadaran masyarakat. Sedangkan untuk manfaat jasa pengaturan lain, ada faktor keterbatasan pengetahuan masyarakat akan isu lingkungan seperti iklim, erosi, dan limbah, sehingga wajar apabila masyarakat tidak terpikir bahwa jasa-jasa lingkungan tersebut penting bagi mereka.

\section{4) Jasa kultural}

Jasa kultural adalah jasa lingkungan yang bersifat non-material. Jasa ini tidak memiliki fungsi pemenuhan kebutuhan fisik, akan tetapi esensial untuk memelihara kualitas hidup, terkait kesehatan mental, kohesi sosial, serta aktualisasi diri. Nilai manfaat jasa kultural didominasi oleh nilai manfaat estetika $(86,5 \%)$ yang diikuti oleh ekowisata $(13,3 \%)$. Total nilai manfaat jasa kultural untuk masing-masing kampung dalam studi ini dapat dilihat pada Tabel 4.

Tabel 4. Nilai manfaat jasa kultural di empat kampung studi

\begin{tabular}{|c|c|c|c|c|c|c|}
\hline \multirow{2}{*}{ No. } & \multirow{2}{*}{ Jasa kultural } & \multicolumn{4}{|c|}{$\begin{array}{c}\text { Nilai Valuasi } \\
\text { (juta USD/tahun) }\end{array}$} & \multirow{2}{*}{ Persentase } \\
\hline & & Bea Nehas & Merabu & Dumaring & $\begin{array}{l}\text { Long } \\
\text { Duhung }\end{array}$ & \\
\hline 1. & Rekreasi & 0,3 & 0,1 & 0,1 & 0,1 & $0,1 \%$ \\
\hline 2. & Estetika & 405,3 & 101,6 & 105,5 & 65,6 & $86,5 \%$ \\
\hline 3. & Ekowisata & 62,4 & 15,6 & 16,2 & 10,1 & $13,3 \%$ \\
\hline \multirow[t]{2}{*}{4.} & Spiritual & 0,3 & 0,1 & 0,1 & 0,05 & $0,1 \%$ \\
\hline & Total & 468,3 & 117,4 & 121,9 & 75,8 & \\
\hline
\end{tabular}

Sumber: hasil pengolahan data (2019)

Kesenjangan dan ketidakpastian. Data valuasi terkait manfaat jasa kultural masih sangat terbatas. Data acuan dari database TEEB yang digunakan untuk menentukan nilai manfaat estetika, lokasinya berada di negara maju dengan tingkat pendapatan dan pendidikan warga yang cukup tinggi. Metode valuasi yang digunakan adalah kontingensi, dimana acuan nilai manfaat adalah kesediaan responden untuk membayar agar manfaat estetika dari hutan tetap dapat mereka nikmati. Dengan pendapatan dan tingkat pendidikan yang tinggi, masyarakat negara maju lebih cenderung memiliki apresiasi yang tinggi terhadap estetika. Konteks apresiasi yang tinggi di sini berbentuk keleluasaan yang lebih secara finansial (van den Berg \& van Rijn, 2015). Sehingga nilai yang bersedia dibayarkan oleh responden pun juga akan lebih tinggi. Hal ini tentu kontras dengan nilai manfaat rekreasi dan ekowisata yang memang datanya diambil dari negara berkembang (Indonesia dan India).

Persepsi masyarakat. Preferensi nilai jasa kultural di tingkat masyarakat lokal, cenderung beririsan satu sama lain. Dalam konteks kepercayaan masyarakat, nilai estetika dan spiritualisme tidak dapat dipisahkan satu sama lain. Dari tata cara ritual adat, dapat terlihat bagaimana eksistensi hutan, estetika, dan spiritualisme saling berkelindan. Salah satu contohnya adalah kriteria material untuk keperluan pelaksanaan ritual adat Dayak Wehea di Bea Nehas. Material ini sifatnya spesifik, tidak dapat digantikan dengan yang lain. Sebuah material selain memiliki fungsi juga memiliki nilai estetika atau keindahannya sendiri. Salah satu keluhan warga Bea Nehas adalah makin sulitnya menemukan kayu bulat dengan diameter setidaknya 3 meter. Kayu bulat ini dibutuhkan untuk membuat peti mati pada ritual pemakaman. Secara fungsional, kayu bulat ini bisa saja digantikan dengan material lain seperti 
seng atau plastik, namun secara estetika tidaklah layak. Kayu secara estetika merupakan representasi kedekatan dengan alam, yang tidak dimiliki seng atau plastik. Ketika representasi itu tidak terpenuhi, maka serta merta ritual tersebut tidak memenuhi kaedah spiritual. Demikian pula misalnya dalam seni tari yang dilakukan dalam upacara adat yang dilakukan sebagai ungkapan syukur kepada dewa-dewa dalam kepercayaan suku Dayak. Penggunaan aksesoris seperti bulu burung enggang, serta gerakan yang terinspirasi gestur elegan hewan tersebut, menunjukkan betapa lingkungan, estetika, dan spiritualisme sesungguhnya sangat erat berkaitan. Oleh karena itu perlu adanya studi lanjut terkait nilai manfaat jasa estetika dan spiritual yang benar-benar merefleksikan sudut pandang masyarakat lokal di Kalimantan Timur.

Nilai ekowisata merupakan potensi yang sangat disadari oleh sebagian masyarakat beberapa kampung dalam studi ini. Upaya memaksimalkan manfaat ekowisata paling ditunjukkan oleh masyarakat Merabu. Kampung Merabu sudah mengembangkan kelembagaan khusus untuk pengelolaan ekowisata di sana. Kampung Dumaring juga telah mengembangkan potensi ekowisatanya dengan fokus pada wisata di kawasan hutan mangrove.

\section{5) Total Economic Value (TEV)}

Dari hasil analisis didapat bahwa keempat kampung dalam studi ini menunjukkan proporsi jasa lingkungan seperti terlihat pada Gambar 1. Dapat dilihat bahwa kategori jasa lingkungan penyediaan, pengaturan, dan kultural memiliki persentase yang cukup signifikan serta tidak ada yang terlampau mendominasi. Jasa penyediaan mengambil porsi yang paling besar yaitu $45,2 \%$. Kontras dengan porsi jasa pendukung sangat kecil yaitu hanya $0,1 \%$ saja.

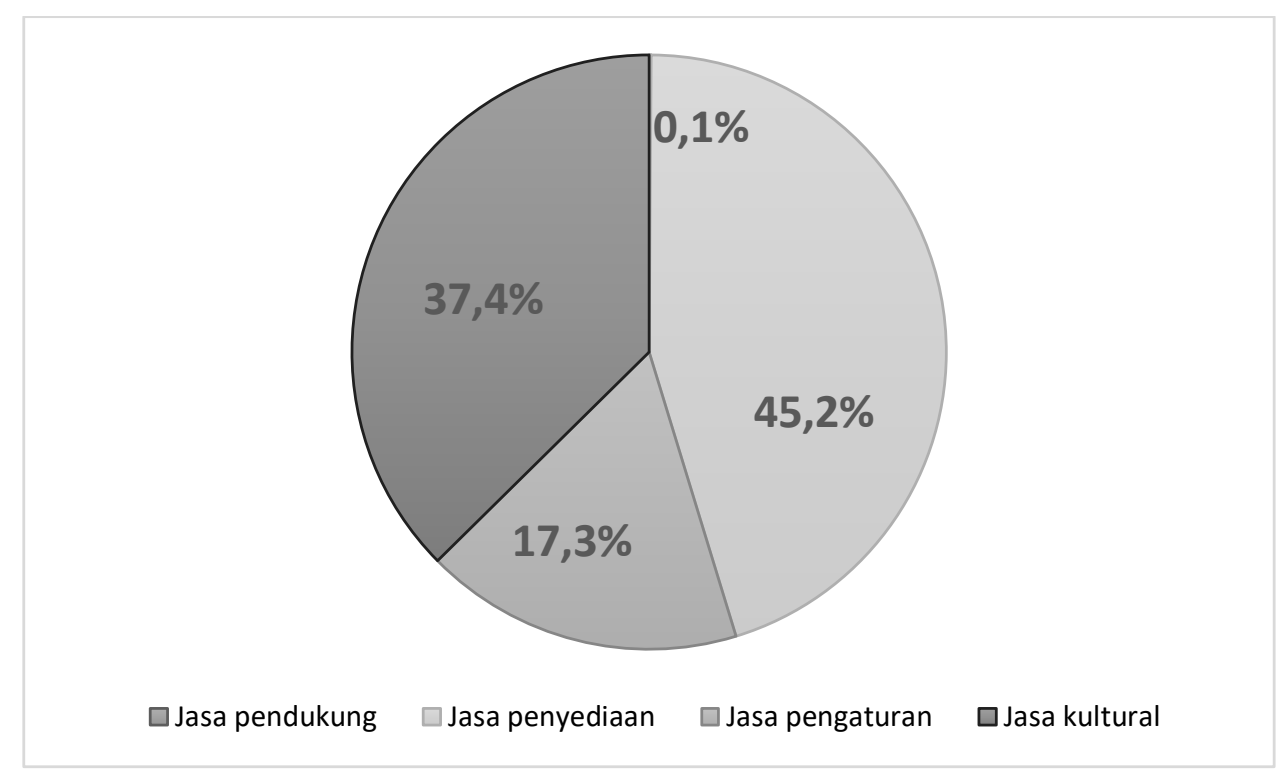

Gambar 1. Proporsi nilai jasa lingkungan terhadap TEV Sumber: hasil pengolahan data, (2019)

Untuk masing-masing kampung nilai TEV dapat dilihat pada Tabel 5. Kampung Bea Nehas memiliki TEV paling besar yaitu mencapai 1,25 milyar USD. Sementara TEV ketiga kampung lainnya hanya berada di kisaran ratusan juta USD. Faktor yang menyebabkan tingginya TEV Bea Nehas adalah karena luasan kawasan hutan yang mencapai 90.930 ha atau empat hingga lima kali lipat luasan ketiga kampung lainnya. Meski begitu, perlu dicatat bahwa sebagian luasan hutan yang diklaim sebagai hutan adat kampung Bea Nehas lokasinya berjarak puluhan 
kilometer dari kawasan kampung. Sehingga nilai TEV untuk kampung Bea Nehas dapat saja mengalami penyesuaian apabila angka luasan tersebut mengalami koreksi.

Tabel 5. Total Economic Value (TEV) di empat kampung studi

\begin{tabular}{|c|c|c|c|c|c|}
\hline \multirow{2}{*}{ No. } & \multirow{2}{*}{ Kategori } & \multicolumn{4}{|c|}{$\begin{array}{c}\text { Nilai Valuasi } \\
\text { (juta USD/tahun) }\end{array}$} \\
\hline & & Bea Nehas & Merabu & Dumaring & Long Duhung \\
\hline 1. & Jasa pendukung & 1,4 & 0,3 & 0,4 & 0,2 \\
\hline 2. & Jasa penyediaan & 565,7 & 141,9 & 147,2 & 91,6 \\
\hline 3. & Jasa pengaturan & 217,1 & 54,4 & 56,5 & 35,2 \\
\hline \multirow[t]{2}{*}{4.} & Jasa kultural & 468,3 & 117,4 & 121,9 & 75,8 \\
\hline & Total Economic Value (TEV) & $1.252,5$ & 314,1 & 325,9 & 202,8 \\
\hline
\end{tabular}

Sumber: hasil pengolahan data (2019)

Kesenjangan dan ketidakpastian. Selain dari adanya kelemahan terkait berbagai metode valuasi yang digunakan dalam studi-studi acuan, faktor ketidakpastian juga bersumber dari data terkait hutan di kawasan kampung studi. Data mengenai hutan kawasan kampung didapat dari dokumen dinas pemerintahan kampung terkait. Data tersebut tidak menggambarkan distribusi kondisi hutan (komposisi dan struktur tegakan, penyebaran jenis pohon, keragaman jenis) dalam satu luasan hutan. Selain itu, ada pula data luasan kawasan hutan yang tidak konsisten antara satu sumber dengan sumber lainnya. Ditambah lagi dengan adanya potensi tumpang tindih kawasan hutan.

Proporsi TEV dimana jasa penyediaan memiliki persentase terbesar, sementara jasa pendukung dan pengaturan jauh lebih kecil, bukanlah indikasi bahwa manfaat jasa penyediaan merupakan jasa lingkungan yang paling esensial. Kesenjangan tersebut merupakan indikasi bahwa metode valuasi untuk jasa lingkungan yang bersifat abstrak, tidak langsung, dan nonmaterial perlu dimutakhirkan. Dengan demikian ke depan proses valuasi jasa lingkungan akan semakin baik dalam merepresentasikan dimensi manfaat jasa lingkungan secara utuh.

\section{KESIMPULAN}

Berdasarkan valuasi jasa lingkungan dari ekosistem hutan tropis di kawasan empat kampung di Kalimantan Timur, didapatkan hasil bahwa TEV untuk kampung Bea Nehas adalah sebesar 1,25 milyar USD/tahun atau setara dengan 18,2 triliun rupiah/tahun. TEV untuk kampung Merabu adalah sebesar 314,1 juta USD/tahun atau setara dengan 4,6 triliun rupiah/tahun. TEV untuk kampung Dumaring adalah sebesar 325,9 juta USD/tahun atau setara dengan 4,7 trilyun rupiah/tahun. Sedangkan, kampung Long Duhung memiliki TEV sebesar 202,8 juta USD/tahun atau setara dengan 2,9 trilyun rupiah. Dari nilai TEV kampung-kampung tersebut, proporsi nilai jasa pendukung adalah sebesar $0,1 \%$, jasa penyediaan sebesar $45,2 \%$, jasa pengaturan sebesar 17,3\%, dan jasa kultural sebesar 37,4\%.

\section{REKOMENDASI}

1. Perlu adanya studi komprehensif yang memetakan faktor-faktor yang membentuk jasa lingkungan yang manfaatnya bersifat abstrak atau tidak langsung, terutama jasa pendukung, jasa pengaturan dan jasa kultural. Dengan demikian, estimasi nilai manfaat dapat lebih merefleksikan manfaat jasa lingkungan secara utuh. Studi lanjutan juga perlu mengakomodir adanya bias preferensi, dan lebih menggali bagaimana kondisi dan latar belakang seperti gaya hidup, pranata sosial, sejarah, cara pandang terhadap dunia (worldview), gender, dan tingkat pendidikan formal mempengaruhi kecenderungan hasil 
valuasi. Selanjutnya, perlu adanya studi khusus untuk mendapatkan gambaran distribusi kondisi kawasan hutan suatu daerah.

2. Pondasi dari gambaran besar nilai manfaat dari jasa lingkungan ekosistem hutan tropis di Kalimantan Timur sebaiknya dibangun dari banyak studi berskala kecil. Sehingga perlu digalakkan penelitian jasa lingkungan di berbagai daerah, baik dalam skala terkecil seperti kampung/desa hingga skala yang lebih besar seperti kabupaten/kota.

\section{DAFTAR PUSTAKA}

Chandini, \& Kumar, Randeep \& Kumar, Ravendra \& Prakash, Om. (2019). The Impact of Chemical Fertilizers on our Environment and Ecosystem. Research Trends in Environmental Sciences, Edition: 2nd, Chapter: 5, pp.69-86.

Gómez-Baggethun, E., de Groot, R., Lomas, P. L., \& Montes, C. (2010). The history of ecosystem services in economic theory and practice: From early notions to markets and payment schemes. Ecological Economics, 69(6), 12091218. doi:10.1016/j.ecolecon.2009.11.007

Johnston, R.J., Rolfe,J., Rosenberger, R.S., \& Brouwer, R. (2015). Introduction to Benefit Transfer Methods: Chapter 2. In Johnston, R.J., Rolfe, J., Rosenberger, R., Brouwer, R. (Eds.) Benefit Transfer of Environmental and Resource Values: A Guide for Researchers and Practitioners. Springer, Netherlands.

Lesser, J. A., \& Feinstein, C. D. (1999). Electric Utility Restructuring, Regulation of Distribution Utilities, and the Fallacy of "Avoided Cost" Rules. Journal of Regulatory Economics, 15(1), 93-110. doi:10.1023/a:1008001008947

Mavsar R., Varela E., Gouriveau, F., Herreros, F. (2013). Methods and tools for socio-economic assessment of goods and services provided by Mediterranean forest ecosystems. Project Report for Component 2 of the project "Optimized production of goods and services by Mediterranean forest ecosystems in the context of global changes", pages 57-60.

Millennium Ecosystem Assessment. (2005). Ecosystems and Human Well-being: Synthesis. Island Press, Washington, DC.

Pascual, U., Muradian, R., Brander, L., Gómez-Baggethun, E., Martín-López, B., Verma, M., Armsworth, P., Christie, M., Cornelissen, H., Eppink, F., Farley, J., Loomis, J., Pearson, L., Perrings, C., Polasky, S., McNeely, J. A., Norgaard, R., Siddiqui, R., David Simpson, R., Simpson, R. D. (2012). The economics of valuing ecosystem services and biodiversity. In The Economics of Ecosystems and Biodiversity: Ecological and Economic Foundations (pp. 183-256). Taylor and Francis. https://doi.org/10.4324/9781849775489

Pemerintah Desa Bea Nehas. (2018). Rencana Pembangunan Jangka Menengah Desa Bea Nehas Tahun 2018 - 2023. Desa Bea Nehas, Kecamatan Muara Wahau.

Pemerintah Kampung Dumaring. (2018). Rencana Pembangunan Jangka Menengah Kampung Merabu Kecamatan Kelay Kabupaten Berau Tahun 2018 - 2023. Kampung Dumaring, Kecamatan Talisayan.

Pemerintah Kampung Long Duhung. (2018). Profil Kampung Long Duhung. Kampung Long Duhung, Kecamatan Kelay.

Pemerintah Kampung Merabu. (2018). Rencana Pembangunan Jangka Menengah Kampung Merabu Kecamatan Kelay Kabupaten Berau Tahun 2014 - 2018. Kampung Merabu, Kecamatan Kelay. 
Secretariat of the Convention on Biological Diversity (2001). The Value of Forest Ecosystems. Montreal, SCBD, 67p. (CBD Technical Series no. 4).

Van Beukering, P.J.H., H.S.J. Cesar and M.A. Jansen (2003) Economic valuation of the Leuser National Park on Sumatra, Indonesia. Ecological Economics 44(1): 43-62.

van den Berg G.J., van Rijn I.A.W. (2015) Cultural Differences in the Appreciation of Art Periods and Art Forms. In: Choudhury P. (eds) Proceedings of the 1996 Multicultural Marketing Conference. Developments in Marketing Science: Proceedings of the Academy of Marketing Science. Springer, Cham.

Van der Ploeg, S. and R.S. de Groot (2010) The TEEB Valuation Database - a searchable database of 1310 estimates of monetary values of ecosystem services. Foundation for Sustainable Development, Wageningen, The Netherlands.

Viets, F. G., \& Lunin, J. (1975). The environmental impact offertilizers. C R C Critical Reviews in Environmental Control, 5(4), 423-453. doi:10.1080/10643387509381630 